\title{
Assessment of the intraday variability of anthropometric measurements in the work environment: a pilot study
}

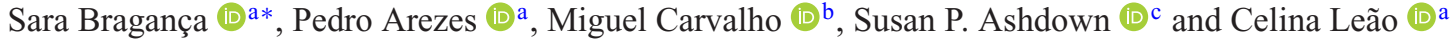 \\ ${ }^{a}$ Department of Production and Systems, University of Minho, Portugal; ${ }^{b}$ Department of Textile Engineering, University of Minho, \\ Portugal; ${ }^{c}$ Department of Fiber Science \& Apparel Design, Cornell University, USA
}

\begin{abstract}
Sitting for long periods of time, both during work and leisure times, is the typical behavior of the modern society. Especially at work, where there is not much flexibility, adopting the sitting posture for the entire day can cause some short-term and long-term effects. As workers' productivity and well-being relies on working conditions, evaluating the effects caused by work postures assumes a very important role. The purpose of this article was to evaluate the variation of some anthropometric measurements during one typical workday to understand whether the known long-term effects can also be seen and quantified in an 8-h period. Twenty participants were measured before and after work, using traditional anthropometry equipment. The data from the two repetitions were compared using statistical tests. The results showed a slight variation in the anthropometric measurements, some with a tendency to increase over time and others with a tendency to decrease.
\end{abstract}

Keywords: sitting posture; anthropometric variation; work

\section{Introduction}

The modern lifestyle has resulted in an often sedentary behavior for a large portion of the population. The sitting posture is one of the work postures that many workers are required to adopt for the majority of their day. Most working adults spend more than a half of their time at work in a sitting posture [1,2]. This long-term behavior, lacking physical activity, may cause some very harmful effects on the human body. In fact, a posture that causes pain or discomfort may lead to a more problematic situation such as work-related musculoskeletal disorders, which will reduce the working capacity and cause productivity losses, absenteeism, lack of productivity and decreased well-being [3-5].

There are many studies proving that a prolonged sitting posture results in several health problems such as obesity, diabetes, some cancers and death from any cause [6-8]. Apart from these problems, there are other changes in the human body that can be experienced daily: leg swelling $[9,10]$, poor blood circulation and varicose veins $[11,12]$, stress on the lower extremity joints [13] and high lumbar disc pressure [14-16].

Despite the fact that knowledge about these problems is not new, the adoption of this sedentary behavior is still a constant in most jobs. Nevertheless, there is a growing concern about what needs to be done in order to promote health and well-being for workers. Research has determined that the most effective way to prevent adverse effects to the human body is by increasing physical activity in the workplace and by promoting postural changes [17-20]. However, it is difficult to define with precision the amount of time that should be spent on each working posture because the optimal proportion of standing and sitting is unknown [21].

Another lack of published research occurs in the analysis of the rate at which the physiological changes in the human body occur. Knowing the physical and psychological effects of a working posture on the human body, as well as quantifying its variation over a period of time, is very important. However, most of the literature is based on the evaluation of the effects of shift work or overtime work $[22,23]$. There are also a few studies that measure the variation of anthropometric measurements related to working conditions. For example, Ishizaki et al. [24] concluded that shift work had a significant impact on the body mass index and on the waist to hip ratio. Research by Nakamura et al. [25] determined that people who worked overtime had more risk of increasing body mass index and waist circumference, regardless of independent lifestyle factors. However, despite the field of expertise, most studies focus solely on the analysis of the variation of weight $[26,27]$ and especially stature [28-32].

According to Corlett [32] the stature decreases quickly after people get out of bed and, depending on the pattern of work and rest, continues to reduce during the day and then overnight recovers to its natural state. This variation

*Corresponding author. Email: saraabraganca@gmail.com 
in stature results from changes in the height of the intervertebral discs - compressive load on the spine causes osmotic pressure of the discal tissues, making them expel a fluid that makes intervertebral joint change its dynamic response [30]. Eklund and Corlett [33] suggest that longterm loading of the discs causes irreversible loss of disc height, damage to the endplates and underlying bone and increases the probability of nerve root pressure and pain. In an experiment performed by the same authors, it was shown that stature decreased about $3.2 \mathrm{~mm}$ when the shoulders are loaded for $1 \mathrm{~h}$ with $14 \mathrm{~kg}$ and decreased about $1.4 \mathrm{~mm}$ when there is no load when performing the same activities. Prolonged static postures, both sitting and standing, cause these changes, which in turn cause pain and discomfort. Both of these postures cause disc degeneration or lower back pain; however, studies of lumbar intradiscal pressure in the standing and sitting postures have mostly reported higher pressures when sitting [34]. In contrast, Hildebrandt [35] reported back pain prevalence in the population working mostly in the standing posture (male construction workers and female nurses). Messing et al. [21] stated that the effects of specific sitting and standing postures on cartilage, muscle and the cardiovascular system may help explain discomfort in the lower extremities. Moreover, they concluded that standing at work without freedom to sit down at will is strongly associated with pain in the lower leg, calf, ankle and foot for both men and women. Also, in Reilly and Freeman's [30] study it became evident that allowing periodic pauses for recovery would help to avoid the decreased responsiveness to spinal loading. Moreover, Beynon and Reilly [36] showed in a 4-h nursing activity that the spinal shrinkage was lower when people could sit down for a 20-min break rather than stand up for the 20-min break, because sitting allowed unloading of the spine and either a reversal or termination of the shrinkage process.

None of the studies reviewed took into consideration many other relevant anthropometric measurements that can also vary over time in response to the working posture adopted. The majority of the literature analyzed describes longitudinal studies; although sometimes the purpose was to evaluate the variability of a specific body measurement in one day. This is the case, e.g., of Robinson and Watson's [37] study that showed small day-to-day fluctuations and concluded that they occurred due to alterations in body water and fat tissue. Longitudinal research is probably the most common because many of the effects of long periods of time in the same posture can only be seen in a long-term reality. However, there is evidence that some variability of anthropometric measurements can be witnessed in a short-term evaluation. As such, the purpose of this article was to present a preliminary study to evaluate the differences that occur in the anthropometric measurement of workers (working in the sitting posture) during a typical 8 -h workday, by comparing the measurements taken at the beginning of the day with those taken at the end of the day.

\section{Materials and methods}

\subsection{Participants}

Twenty-four working adults, 11 females and 13 males, with ages ranging from 23 to 55 years $(29.64 \pm 6.96)$ participated in this study. Female participants were on average 28.00 years old, $1586.2 \mathrm{~mm}$ in stature and $60.03 \mathrm{~kg}$ in weight. Male participants were on average 30.85 years old, $1746.2 \mathrm{~mm}$ in stature and $79.25 \mathrm{~kg}$ in weight.

The participants were selected based on the working posture they usually adopt during work. Only full-time employees who work predominantly in the sitting posture or have only occasional standing moments were selected. Of the 24 people selected, 8 affirmed they only worked in the sitting posture while 16 claimed they worked mainly seated but with occasional standing periods.

The participants worked at a university and a research institution. Participation in this study was on a voluntary basis and the participants were contacted via email or in person. When contacted, they were informed of the detailed procedures and requirements of the test and were asked about their usual working posture.

Participants were excluded from this test if they exercised or practiced any sport activities before the test (exercise can produce dehydration and/or increased blood flow, which may affect body mass and girth measurements).

This study was approved by the host institution's ethic committee and written informed consent was obtained from all participants prior to the study.

\subsection{Data collection}

Before the data collection process, all of the procedures and the purpose of the study were explained to the participants. They were informed that they would be required to remove their clothing and be measured in their own underwear in order to obtain accurate measurements.

A single anthropometrist, certified by the International Society for the Advancement of Kinanthropometry (ISAK), collected the anthropometric data using traditional anthropometry equipment (anthropometer, caliper and measuring tape). This choice of technique, which was based on the procedures defined by ISAK and Standard No. ISO 7250:2008 [38], was due to the anticipated small variation in the measurements that could not be recorded with precision and reliability with the equipment available for this study.

Although a 3D body scanner was available, testing had shown that this particular model did not provide precise results. The measurements collected represent the body parts where more significant differences were expected to be found. They were divided in four categories: basic, girths, lengths and breadths. All of the measurements are presented in Table 1.

Some of the measurements were taken in the standing posture while others were taken with the participants seated on a stool adjustable in height. All of the landmarks were 
Table 1. Measurements collected for the study.

\begin{tabular}{lclll}
\hline Type & ID number & \multicolumn{1}{c}{ Measurement } & Posture & Instrument \\
\hline Basic & 1 & Weight & Standing & Weighing scale \\
& 2 & Stature & Standing & Anthropometer \\
& 3 & Sitting height & Sitting & Anthropometer \\
Girths & 4 & Waist & Standing & Measuring tape \\
& 5 & Hip (gluteal) & Standing & Measuring tape \\
& 6 & Thigh & Standing & Measuring tape \\
& 7 & Mid-thigh & Standing & Measuring tape \\
& 8 & Calf & Standing & Measuring tape \\
& 9 & Ankle & Standing & Measuring tape \\
Lengths & 10 & Tibiale laterale & Standing & Anthropometer \\
& 11 & Iliocristale height & Standing & Anthropometer \\
& 12 & Omphalion height standing & Standing & Anthropometer \\
& 13 & Cervicale height standing & Standing & Anthropometer \\
& 14 & Acromial height & Standing & Anthropometer \\
& 15 & Omphalion height sitting & Sitting & Anthropometer \\
& 16 & Cervicale height sitting & Sitting & Anthropometer \\
Breadths & 17 & Biiliocristal & Standing & Anthropometer \\
& 18 & Biepicondyal femur & Sitting & Anthropometer \\
\hline
\end{tabular}

identified through palpation and the specific sites were then marked on the participant's body with a washable black eyeliner. A Harpenden portable anthropometer (Holtain, UK) was used for lengths and breadths and a regular measuring tape was used for girths. A representation of the measurements of the body is shown in Figure 1.

Every participant was measured twice on the same day. The measurements took place in two distinct periods of time: (a) in the morning, at the beginning of the working day, in a period ranging approximately from 09:00 to $11: 00$; (b) in the afternoon, at the end of the working day, from 16:30 to $18: 30$. Because of this fact, there was a limitation to measure only four people per day, considering that one measuring session took, on average, $30 \mathrm{~min}$.

The measurement process took place in small rooms very close to the participants' workplace, within approximately 1-min walking from their desks. The rooms were carefully selected so they could be as close to the participants as possible.

After the measurement process, the participants were asked to complete a short demographic questionnaire about their age, profession, any history of medical problems

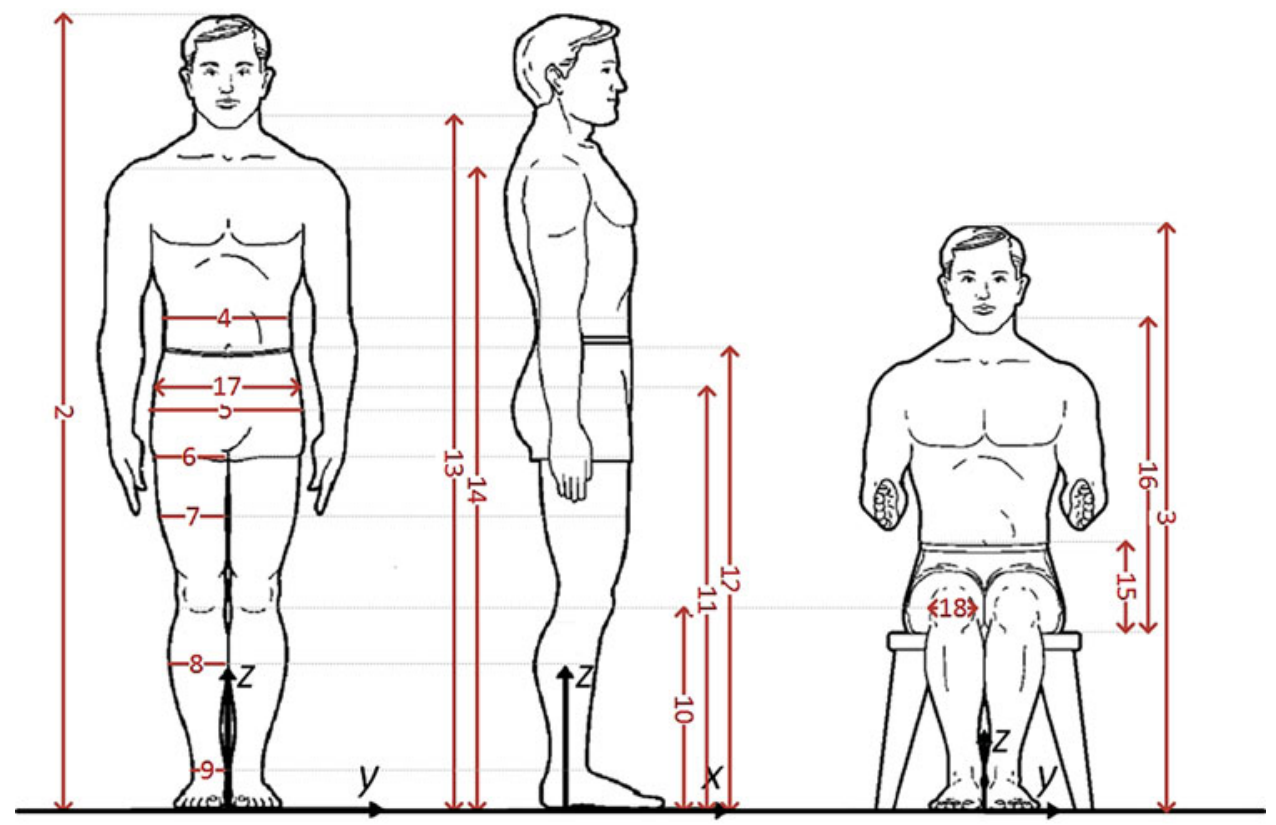

Figure 1. Representation of the measurements of the body.

Note: see Table 1 for identification of measurements. 
and, most importantly, questions regarding their working posture and its impact on their comfort.

\subsection{Data analysis}

First of all, the data were checked for possible errors and missing values. After that, a search was made for possible outliers. If there were values higher or lower than three standard deviations they were considered abnormal and discarded $(M \pm 3 S D)$. The Shapiro-Wilk test was then performed to verify the normality of the data considered. All of the analyses were carried out using the statistical software SPSS version 23 for Mac.

Several statistical tests were conducted to understand the influence of the period of time on the changes in the anthropometric measurements. The analyses performed took into consideration not the totality of the data but the differences between the measurements taken at the beginning of the day (T1) and the measurements taken at the end of the day (T2): Difference $=\mathrm{T} 1-\mathrm{T} 2$. These tests were used to given an answer to the following research hypotheses:

$H_{1}$ : there are differences between the intraday
measurements;

$H_{2}$ : weight and measurements of the type 'girth' and 'breadth' have the tendency to increase over time;

$\mathrm{H}_{3}$ : stature and measurements of the type 'length' and 'height' have the tendency to decrease over time.

A paired-samples $t$ test with the significance level set at $0.05(\alpha=0.05)$ was used to compare the means of the differences of the measurements collected in each period of time. The lower the resulting $p$ value, the higher the significance of the difference.

The Friedman test was used to identify which measurements had similar behaviors. This information was used to create groups of measurements that showed the same trend (measurements either increased or decreased over time). The groups were created by sorting (ascending and descending) the Friedman mean rank and comparing it with the median of the differences between the two periods of time. The ascending order corresponded to median values that were first negative and then positive, whereas the descending order corresponded to the opposite. All of the values with the same sign $(+$ or - ) formed an initial group. New measurements were gradually added until the $p$ value was below 0.05 , i.e., at the point where the null hypothesis was rejected. This procedure was repeated for both of the data groups. The interception of the two groups, i.e., the measurements that when added still allowed for the $p$ value to be lower than 0.05 , formed a new group.

\section{Results}

The Shapiro-Wilk test showed that the data followed a normal distribution. The errors in the data were corrected and no outliers were found. The data respected all of the assumptions of every statistical test (especially no violation of normality, linearity or homoscedasticity for the Pearson correlation, which is a highly sensitive test).

Some descriptive statistics (range, mean and standard deviation) of the collected data are presented in Table 2.

The mean of the differences between the measurements taken at the beginning of the day and the measurements taken at the end of the day $(\mathrm{T} 1-\mathrm{T} 2)$ as well as the standard deviation and median were calculated and are presented in Table 3.

Negative results mean that the measurements had a lower value at the beginning of the day than at the end of the day, i.e., increased over time, whilst positive values indicate that the measurements had a higher value at the beginning of the day than at the end of the day, i.e., decreased over time.

Table 4 presents the results of the paired-samples $t$ test, where it can be seen that there are some differences that have a statistical significance (identified with an asterisk) and others that do not.

The results of the Friedman test are presented in Table 5, as well as the significance level - ordered both from the lowest to the highest value and from the highest to the lowest value - and the resulting groups.

\section{Discussion}

Understanding what happens to the human body throughout the working day is very useful to diverse applications. The shape and size of our body parts change over time as a result of the working postures adopted for long periods of time and the consequent fatigue. The effects underlying each working posture are the results of the accumulation of time spent on a determined working posture contributing to comfort and health problems.

In the present study there was some variability in the anthropometric characteristics of the sample analyzed. For example, the tallest person measured approximately $1900 \mathrm{~mm}$ whilst the shortest person measured only $1500 \mathrm{~mm}$. Nevertheless, there were some measurements where the variability was not very large, as in the cases of the biepicondyal femur breadth (SD $9.4 \mathrm{~mm})$, the ankle girth $(S D 14.6 \mathrm{~mm})$ or the omphalion height when sitting (SD $18.5 \mathrm{~mm})$.

The sample analyzed was a good representation of the average population (e.g., according to Barroso et al. [39] the average stature and weight of the general population are $1627.5 \mathrm{~mm}$ and $69.00 \mathrm{~kg}$ respectively and the average stature and weight of this study's population are $1672.2 \mathrm{~mm}$ and $70.53 \mathrm{~kg}$ respectively).

When comparing the means of the differences for each measurement with the paired-samples $t$ test, it was 
Table 2. Descriptive statistics of the results.

\begin{tabular}{lrrc}
\hline Measurement & \multicolumn{1}{c}{$M$} & \multicolumn{1}{c}{$S D$} & Range \\
\hline 1. Weight & 705.30 & 13.49 & $473.00-975.00$ \\
2. Stature & 1672.20 & 10.09 & $1505.00-1897.00$ \\
3. Sitting height & 870.60 & 5.19 & $751.00-966.00$ \\
4. Waist girth & 794.70 & 10.32 & $648.00-1044.00$ \\
5. Hip girth & 991.30 & 6.99 & $875.00-1188.00$ \\
6. Thigh girth & 580.30 & 4.49 & $484.00-644.00$ \\
7. Mid-thigh girth & 534.00 & 4.20 & $446.00-607.00$ \\
8. Calf girth & 370.60 & 2.84 & $303.00-418.00$ \\
9. Ankle girth & 223.40 & 1.46 & $200.00-270.00$ \\
10. Tibiale laterale length & 467.50 & 3.52 & $397.00-568.00$ \\
11. Iliocristale height & 993.40 & 7.90 & $839.00-1183.00$ \\
12. Omphalion height standing & 985.00 & 7.40 & $856.00-1165.00$ \\
13. Cervicale height standing & 1413.80 & 9.32 & $1256.00-1632.00$ \\
14. Acromial height & 1349.80 & 8.93 & $1198.00-1547.00$ \\
15. Omphalion height sitting & 213.20 & 1.85 & $180.00-260.00$ \\
16. Cervicale height sitting & 616.50 & 3.60 & $562.00-687.00$ \\
17. Biiliocristal breadth & 327.10 & 3.67 & $270.00-415.00$ \\
18. Biepicondyal femur breadth & 98.60 & 0.94 & $79.00-117.00$ \\
\hline
\end{tabular}

Note: Measurements in millimeters, except weight, which is in kilograms.

Table 3. Differences between the measurements at the beginning of the day and at the end of the day.

\begin{tabular}{lrrrc}
\hline Measurement & $M$ & $S D$ & $M d n$ & Range \\
\hline 1. Weight & -1.83 & 0.458 & -2.00 & $17.00-7.00$ \\
2. Stature & 1.42 & 0.790 & 1.00 & $15.00-17.00$ \\
3. Sitting height & 4.17 & 1.135 & 3.00 & $30.00-18.00$ \\
4. Waist girth & -6.12 & 1.346 & -6.00 & $31.00-37.00$ \\
5. Hip girth & 1.92 & 1.003 & 1.00 & $26.00-18.00$ \\
6. Thigh girth & 5.67 & 0.781 & 6.00 & $20.00-13.00$ \\
7. Mid-thigh girth & 3.00 & 0.451 & 3.50 & $11.00-5.00$ \\
8. Calf girth & -1.67 & 0.324 & -2.00 & $7.00-7.00$ \\
9. Ankle girth & -0.83 & 0.325 & 0.00 & $3.00-13.00$ \\
10. Tibiale laterale length & -0.67 & 0.884 & -1.00 & $16.00-13.00$ \\
11. Iliocristale height & 0.58 & 2.143 & -1.50 & $58.00-53.00$ \\
12. Omphalion height standing & 5.33 & 1.773 & 4.50 & $60.00-24.00$ \\
13. Cervicale height standing & 1.67 & 0.997 & 0.50 & $20.00-18.00$ \\
14. Acromial height & -2.67 & 0.930 & -6.00 & $16.00-16.00$ \\
15. Omphalion height sitting & -0.12 & 1.140 & 0.50 & $21.00-28.00$ \\
16. Cervicale height sitting & 1.88 & 1.130 & 2.50 & $26.00-17.00$ \\
17. Biiliocristal breadth & -0.21 & 0.668 & 0.00 & $15.00-14.00$ \\
18. Biepicondyal femur breadth & -1.33 & 0.217 & -1.50 & $4.00-6.00$ \\
\hline
\end{tabular}

Note: Measurements in millimeters, except weight, which is in kilograms.

concluded that there were only five measurements where the differences were statistically significant (variables with asterisks in Table 4). The thigh girth was the measurement that presented the lowest $p$ value, whereas the waist girth had the highest $p$ value. Moreover, the thigh and the mid-thigh girths showed a $p$ value even lower than 0.005 , meaning that if the level of significance of the study would be much smaller these measurements would still not show statistically significant differences.
The Friedman test made it possible to divide the 18 measurements into three distinct groups according to their behavior. The first group included seven measurements (waist girth; weight; acromial height; calf girth; biepicondyal femur breadth; iliocristale height; tibiale laterale length) and represents the measurements that have more tendency to increase over time. The second group was composed of nine measurements (biiliocristal breadth; ankle girth; omphalion height sitting; height; 
S. Bragança et al.

Table 4. Results of the paired-samples $t$ test.

\begin{tabular}{lrcc}
\hline Measurement & $t$ & $d f$ & Sig. (2-tailed) \\
\hline 1. Weight (T1 - T2) & -1.920 & 23 & 0.067 \\
2. Stature (T1 - T2) & 0.860 & 23 & 0.399 \\
3. Sitting height (T1 - T2) & 1.765 & 22 & 0.091 \\
4. Waist girth (T1 - T2) & -2.182 & 23 & $0.040^{*}$ \\
5. Hip girth (T1 - T2) & 0.916 & 23 & 0.369 \\
6. Thigh girth (T1 - T2) & 3.478 & 23 & $0.002^{* *}$ \\
7. Mid-thigh girth (T1 - T2) & 3.191 & 23 & $0.004^{* *}$ \\
8. Calf girth (T1 - T2) & -2.470 & 23 & $0.021^{*}$ \\
9. Ankle girth (T1 - T2) & -1.230 & 23 & 0.231 \\
10. Tibiale laterale length (T1 - T2) & -0.361 & 23 & 0.721 \\
11. Iliocristale height (T1 - T2) & 0.131 & 23 & 0.897 \\
12. Omphalion height standing (T1 - T2) & 1.443 & 23 & 0.163 \\
13. Cervicale height standing (T1 - T2) & 0.801 & 23 & 0.431 \\
14. Acromial height (T1 - T2) & -1.375 & 23 & 0.182 \\
15. Omphalion height sitting (T1 - T2) & -0.053 & 23 & 0.959 \\
16. Cervicale height sitting (T1 - T2) & 0.796 & 23 & 0.434 \\
17. Biiliocristal breadth (T1 - T2) & -0.15 & 23 & 0.882 \\
18. Biepicondyal femur breadth (T1 - T2) & -2.943 & 23 & $0.007^{*}$ \\
\hline
\end{tabular}

${ }^{*} p<0.05$ statistically significant difference.

$* * p<0.005$.

Note: $\mathrm{T} 1-\mathrm{T} 2=$ difference between the measurements taken at the

beginning of the day (T1) and the measurements taken at the end of the day

(T2); Sig. = significance.

Table 5. Results of the Friedman test and the resulting groups.

\begin{tabular}{lcccc}
\hline Measurement & $\begin{array}{c}\text { Friedman } \\
\text { mean rank }\end{array}$ & $\begin{array}{c}\text { Asymp. sig. } \\
\text { (higher to } \\
\text { lower) }\end{array}$ & $\begin{array}{c}\text { Asymp. sig. } \\
\text { (lower to } \\
\text { higher) }\end{array}$ & Group \\
\hline Waist girth & 6.420 & 0.230 & $0.001^{*}$ & 1 \\
Weight & 7.480 & & $0.003^{*}$ & $0.009^{*}$ \\
Acromial height & 7.500 & & $0.010^{*}$ & \\
Calf girth & 7.920 & & $0.026^{*}$ & \\
Biepicondyal femur breadth & 8.350 & & $0.046^{*}$ & \\
Iliocristale height & 8.600 & & $0.044^{*}$ & \\
Tibiale laterale length & 8.770 & 0.244 & \\
Biiliocristal breadth & 9.100 & 0.133 & \\
Ankle girth & 9.190 & 0.159 & \\
Omphalion height sitting & 9.580 & 0.149 & \\
Stature & 10.000 & 0.118 & \\
Cervicale height standing & 10.040 & 0.129 & \\
Hip girth & 10.350 & 0.166 & \\
Cervicale height sitting & 10.420 & 0.109 & \\
Omphalion height standing & 10.790 & 0.058 & \\
Sitting height & 11.480 & $0.012^{*}$ & & \\
Mid-thigh girth & 11.810 & $0.001^{*}$ & & \\
Thigh girth & 13.190 & & & \\
\hline
\end{tabular}

$* p<0.05$ statistically significant difference.

Note: Asymp. sig. = asymptomatic significance.

cervicale height standing; hip girth; cervicale height sitting; omphalion height standing; sitting height) and represents the in-between measurements with not very clear behavior, meaning they can slightly increase or decrease. The third group comprised only two measurements (midthigh girth; thigh girth) and represents the measurements that have more tendency to decrease over time.
Because the statistical tests did not show very conclusive results, a more empirical approach was followed the analysis of the differences between the measurements. The analysis of the mean of the differences between the morning and afternoon measurements revealed that half of the measurements had negative values $(\mathrm{T} 1<\mathrm{T} 2)$ and half had positive values $(\mathrm{T} 1>\mathrm{T} 2)$. Measurements such as 
weight, waist girth, calf girth, ankle girth, tibiale laterale length, acromial height, omphalion height sitting, biiliocristal breadth and biepicondyal femur breadth had more propensity to increase during the day, while measurements like stature, sitting height, hip girth, thigh girth, mid-thigh girth, iliocristale height, omphalion height standing, cervicale height standing and cervicale height sitting had more propensity to decrease during the day. The differences recorded were very small and were not the same for every individual. The measurement that showed the largest variation between individuals was the iliocristale height (SD $21.43 \mathrm{~mm}$ ), followed by the omphalion height standing $(S D 17.73 \mathrm{~mm})$. In general, the greatest difference was registered for the waist girth, with an average decrease of $6.12 \mathrm{~mm}$, and the smallest difference was recorded for the omphalion height when sitting, with an average decrease of $0.12 \mathrm{~mm}$. Figure 2 demonstrates the values for all of the mean differences.

These results show that differences between the measurements do exist, but some differences are very small and some are not statistically significant. Table 6 presents the differences between morning and afternoon measurements for every participant (full color version available online). The measurements are ordered according to the results of the Friedman mean rank test.

It can be seen that some measurements have the tendency to increase while others tend to decrease, i.e., some measurements are more negative (more red) and others more positive (more green). This can be interpreted as an overall tendency that is shown for most participants.

In the first five measurements (waist girth; weight; acromial height; calf; biepicondyal femur breadth) an increasing trend can be witnessed for the vast majority of the participants. On the other hand, the last four measurements (omphalion height when standing; sitting height; mid-thigh; thigh) demonstrate a decreasing tendency for most participants. In both situations there are only a few cases where there is no difference or where the difference occurs in the opposite direction. The distribution of the differences was not exactly the same for all participants but it had many commonalities. On average, for every participant, eight measurements showed a tendency to decrease, nine measurements a tendency to increase and one measurement to remain the same.

Some trials were made to try to identify a relationship between personal characteristics (e.g., tall persons vs. short persons or people who self-reported that they remained seated for most of the day compared with those who said they were up and down more) and the increasing or decreasing trend. However, with the sample under study it was not possible to verify this relationship. For example, when comparing the first and second persons who had more measurements with a tendency to decrease, it was found that the first approximately weighed $53 \mathrm{~kg}$ and measured $1580 \mathrm{~mm}$ while the latter approximately weighed $96 \mathrm{~kg}$ and measured $1700 \mathrm{~mm}$. The same inconsistency was verified when analyzing the participants who had more measurements with a tendency to increase (one weighed $47 \mathrm{~kg}$ and measured $1500 \mathrm{~mm}$ and the other $74 \mathrm{~kg}$ and $1850 \mathrm{~mm})$.

Based on the literature $[21,32,33,37]$ and as stated in the earlier hypotheses, there is an expected behavior for the different measurements, i.e., some measurements are expected to increase (as the girths and the weight) while others are expected to decrease (as the heights).

Table 7 demonstrates the expected behavior for each one of the measurements, as well as the behavior that was observed from the results of this study. The measurements that had the same behavior on the tests as was expected are indicated.

As can be seen, 11 of the 18 measurements analyzed had the behavior that was expected in every test. However, the remaining seven had a contrasting behavior. Nevertheless, when analyzing each measurement individually

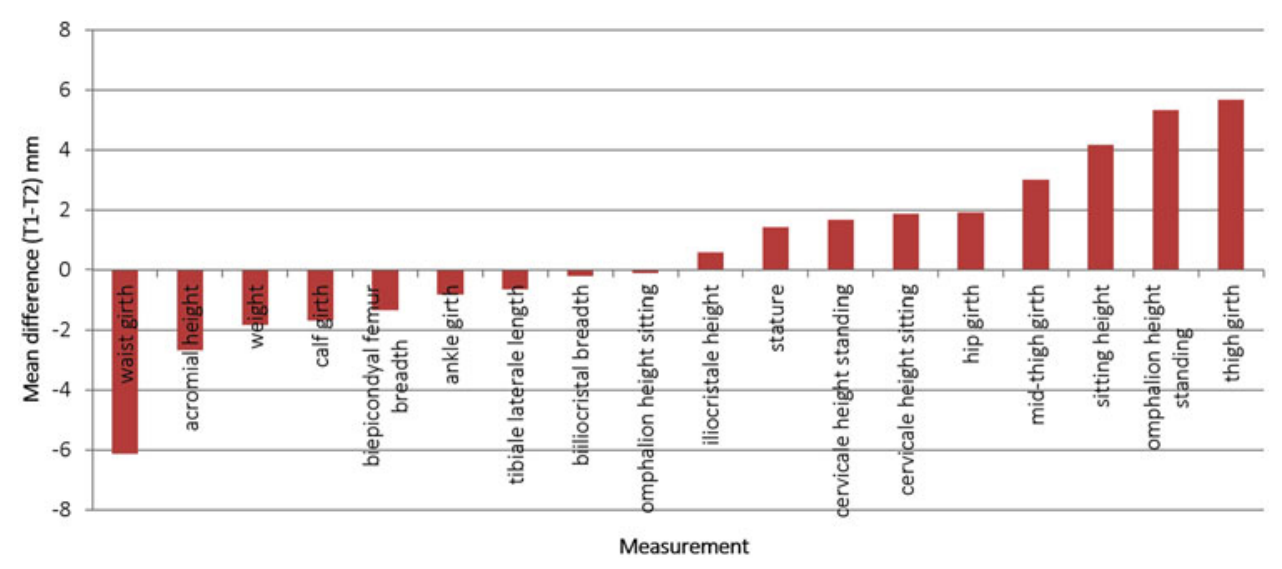

Figure 2. Mean differences.

Note: $\mathrm{T} 1-\mathrm{T} 2=$ difference between the measurements taken at the beginning of the day $(\mathrm{T} 1)$ and the measurements taken at the end of the day (T2). 
Table 6. Differences between measurements for every participant.

\begin{tabular}{|c|c|c|c|c|c|c|c|c|c|c|c|c|c|c|c|c|c|c|}
\hline \multirow{2}{*}{ 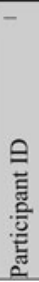 } & \multicolumn{7}{|c|}{ Group 1} & \multicolumn{8}{|c|}{ Group 2} & \multicolumn{3}{|c|}{ Group 3} \\
\hline & 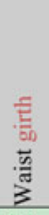 & $\begin{array}{l}\frac{\overrightarrow{0}}{50} \\
3\end{array}$ & 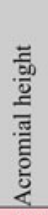 & 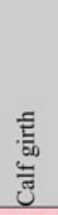 & 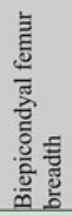 &  & 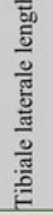 & 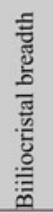 & 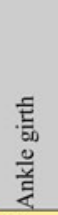 & 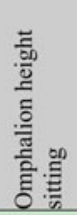 & 总 & 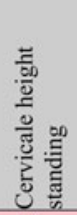 & $\begin{array}{l}\text { 寍 } \\
\text { 呈 }\end{array}$ & 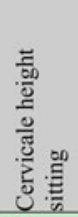 & 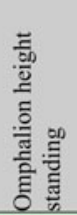 & 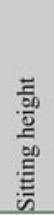 & 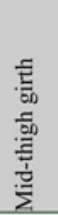 & $\begin{array}{l}\text { 䓌 } \\
\text { 总 } \\
\text { 总 }\end{array}$ \\
\hline 1 & 0.4 & -0.1 & -0.9 & -0.6 & 0.3 & -0.7 & 0.8 & -0.3 & 0 & 0.8 & -0.2 & -0.4 & -1.3 & 0.6 & 1.1 & 0.1 & 0.1 & 1.3 \\
\hline 2 & -1.3 & 1.7 & 1.5 & -0.3 & -0.2 & 0 & 0.7 & 0.2 & -1.3 & 1 & -0.2 & 1.5 & 2 & 0 & 0 & -1 & -0.5 & 0.7 \\
\hline 3 & -1.1 & -0.7 & 0.5 & 0.7 & -0.2 & 1 & -0.3 & -1.4 & 0 & 1 & 1 & -0.3 & -0.8 & 1 & 2 & 1 & -0.3 & -1.3 \\
\hline 4 & -2.8 & -0.4 & 1 & 0 & -0.1 & 1.5 & 0.4 & -0.2 & 0.3 & 0 & 0.5 & -1 & 0.7 & 0.5 & -0.5 & 1 & 0.4 & 0.6 \\
\hline 5 & -1.1 & 0 & 0 & -0.3 & -0.6 & 1.5 & 1 & 1.5 & -0.1 & 0 & 1.2 & 0 & 0.6 & 1 & 0.5 & 3 & -0.1 & 2 \\
\hline 6 & 1.4 & 0 & -0.1 & -0.6 & 0.1 & -0.6 & 1.5 & 0.4 & -0.5 & -0.7 & 0.7 & 0.4 & -0.2 & 0.6 & 1.5 & 0.1 & 0.9 & 0.1 \\
\hline 7 & -0.7 & 0 & -0.9 & -0.2 & -0.6 & 1.6 & 1.6 & -1.2 & 0 & -1.1 & 1 & -0.4 & 2.6 & -0.6 & 1.7 & 0.5 & 0.4 & 1.7 \\
\hline 8 & -1.3 & -0.7 & -0.6 & 0.2 & -0.2 & -0.4 & -1.1 & -0.6 & 0.3 & 0.2 & 0.4 & 1.8 & -0.2 & 0.8 & 0.4 & 0.4 & 0.5 & 1.1 \\
\hline 9 & 0.5 & -0.2 & -1.4 & 0.3 & 0.4 & -0.3 & -1 & 0.9 & -0.1 & 2 & 0.2 & -0.9 & 1.8 & 0 & 0.9 & 0 & 0.3 & 0.8 \\
\hline 10 & -1.4 & 0 & 0.6 & 0 & 0 & 0.3 & -1.3 & -0.3 & 0.1 & -1.3 & 0 & 1.1 & 0.3 & -0.1 & -0.3 & -0.1 & 0.1 & 1.2 \\
\hline 11 & -0.1 & -0.4 & -1.2 & -0.2 & -0.1 & -3.1 & -0.7 & -0.8 & 0 & -2.8 & -0.6 & -0.3 & -0.5 & -1 & -1.7 & -0.2 & 0 & -0.1 \\
\hline 12 & 3.1 & -0.5 & -1 & -0.4 & -0.1 & -0.9 & 0 & 0.9 & -0.1 & -1.9 & -1.7 & -0.7 & -1.8 & -0.3 & 0.3 & -1.1 & 1.1 & 0.6 \\
\hline 13 & -0.4 & 0.1 & -0.4 & 0 & 0 & 1.1 & -1.3 & 0.5 & 0.1 & -1.4 & 0.3 & 1.6 & -0.7 & -1.3 & 1.1 & 2 & 1.1 & -0.2 \\
\hline 14 & -3.7 & -0.2 & -0.7 & -0.5 & -0.2 & 4.2 & 0 & -0.2 & 0.1 & 0.4 & -0.3 & 0.1 & 0.3 & -0.1 & 6 & 1.1 & 0.8 & -0.9 \\
\hline 15 & -0.2 & -0.4 & -1.1 & -0.3 & 0 & -5.3 & -0.7 & 0.4 & 0.3 & -0.5 & 1 & 0 & 1.3 & -1.4 & -1.9 & 0.2 & 0.7 & 1.9 \\
\hline 16 & -1 & -0.3 & 0.1 & -0.5 & -0.1 & 1.3 & -0.2 & -0.1 & -0.4 & 2.1 & 1.5 & 1.5 & 0.3 & 2.6 & 0.5 & 2.2 & 0.1 & 0.5 \\
\hline 17 & -0.4 & 0.1 & -1.6 & 0.1 & -0.4 & -0.1 & 0.4 & 0.3 & 0.2 & 0.1 & 1.2 & 0.5 & -0.2 & 1.2 & 0.7 & 1.5 & 0.6 & 0.8 \\
\hline 18 & 0.7 & -0.5 & -1.2 & -0.3 & -0.1 & -0.6 & 1 & -0.4 & -0.4 & 0.7 & -0.9 & -1.4 & 0.1 & -1.7 & -2.4 & -1.8 & -0.3 & 0.4 \\
\hline 19 & -1.8 & -0.6 & 0.8 & -0.7 & -0.2 & 0 & 0.9 & 0.3 & -0.1 & 1.3 & 0.1 & 0.5 & 1 & 1 & 0.7 & 1 & 0.1 & 0.5 \\
\hline 20 & -1.3 & -0.2 & -0.6 & 0 & -0.2 & -1.3 & -1.2 & -1 & -0.1 & -0.1 & -0.2 & -1.8 & 0.1 & -1.4 & -0.4 & -0.9 & -0.1 & 0.1 \\
\hline 21 & 0.3 & -0.2 & -1.2 & -0.4 & -0.2 & -1.2 & -0.9 & 0.2 & -0.2 & -0.7 & -1.4 & 0.4 & 0.2 & -1.2 & -1.5 & -0.3 & 0.7 & 0.3 \\
\hline 21 & -1.9 & -0.5 & -0.6 & -0.2 & -0.2 & -0.2 & -0.6 & 0.4 & 0 & 0 & 0.1 & 0.2 & -0.8 & 2.3 & 0.4 & 1.5 & 0.4 & 0.9 \\
\hline 23 & -0.1 & -0.3 & 1.6 & 0.2 & -0.1 & 5.8 & -0.7 & 0.1 & -0.1 & 0.2 & -0.2 & 2 & 0.1 & 1 & 4.1 & -1 & -0.4 & -0.3 \\
\hline 24 & -0.5 & -0.1 & 1 & 0 & -0.2 & -2.2 & 0.1 & -0.1 & 0 & 0.4 & -0.1 & -0.4 & -0.3 & 1 & -0.4 & 0.8 & 0.6 & 0.9 \\
\hline
\end{tabular}

Note: Color coded with 'no changes' in yellow, 'negative changes' in red and 'positive changes' in green. The full color version of this table is available online.

Table 7. Expected trend versus test result.

\begin{tabular}{|c|c|c|}
\hline Measurement & Expected & Test result \\
\hline Weight & Increase & Increase \\
\hline Stature & Decrease & Decrease \\
\hline Sitting height & Decrease & Decrease \\
\hline Waist girth & Increase & Increase \\
\hline Hip girth & Increase & Decrease \\
\hline Thigh girth & Increase & Decrease \\
\hline Mid-thigh girth & Increase & Decrease \\
\hline Calf girth & Increase & Increase \\
\hline Ankle girth & Increase & Increase \\
\hline Tibiale laterale length & Decrease & Increase \\
\hline Iliocristale height & Decrease & Decrease \\
\hline Omphalion height standing & Decrease & Decrease \\
\hline Cervicale height standing & Decrease & Decrease \\
\hline Acromial height & Decrease & Increase \\
\hline Omphalion height sitting & Decrease & Increase \\
\hline Cervicale height sitting & Decrease & Decrease \\
\hline Biiliocristal breadth & Increase & Increase \\
\hline Biepicondyal femur breadth & Increase & Increase \\
\hline
\end{tabular}

Note: Bold denotes the measurements that had the same behavior on the tests as was expected.

it can be seen that most of them have very small differences between the morning and the afternoon recording; they are all less than $5 \mathrm{~mm}$. These analyses make it possible to answer the research hypotheses formulated in the methodology section, as detailed in Table 8 .
Hypotheses $\mathrm{H}_{2}$ and $\mathrm{H}_{3}$ are partially accepted because only a few body measurements did not follow the preposition (measurements showing a tendency to increase over time). The hip girth, thigh girth and mid-thigh girth all showed signs of a decreasing tendency, contrary to what was described in research hypothesis $\mathrm{H}_{2}$. Likewise, the tibiale laterale length, the acromial height and the omphalion height when sitting revealed an increasing tendency contrary to what was expressed in research hypothesis $\mathrm{H}_{3}$.

The sample size seemed to be the major limitation of this study. Perhaps with a larger sample size the results would be more conclusive. However, the authors believe that an extremely larger sample size would be needed to provide more robust results. For such a sample size, more extensive resources would be needed for incentives to recruit more participants than was possible for this study, which relied on those who would donate their time twice in one day without any financial compensation.

Another fact that may have contributed to these not very conclusive results was the time span considered. Only one 8 -h interval is a relatively small amount of time to study the small alterations that occur in the human body. Instead of a cross-sectional study, it would be interesting to perform a longitudinal study where the participants would be measured every day over a period of time so that more data could be taken into consideration. In fact, 
Table 8. Hypotheses decision and justification.

\begin{tabular}{lll}
\hline Hypothesis & Decision & Justification \\
\hline$H_{1}$ & Accept & $\begin{array}{c}\text { Analysis of the differences between the measurements (T1 - T2) showed that there are variations in } \\
\text { the values. The paired-samples } t \text { test demonstrated that four of these differences are statistically } \\
\text { significant } \\
H_{2}\end{array} H_{3} \quad$ Partially accept \\
$\begin{array}{c}\text { Some of the measurements (hip girth; thigh girth; mid-thigh girth) showed a tendency to decrease, } \\
\text { contrary to what was expected } \\
\text { Most measurements of the type 'length' and 'height' showed a tendency to decrease. The only } \\
\text { exception occurred for tibiale laterale length, acromial height and omphalion height sitting }\end{array}$ \\
\hline
\end{tabular}

Note: $\mathrm{T} 1-\mathrm{T} 2=$ difference between the measurements taken at the beginning of the day (T1) and the measurements taken at the end of the day (T2).

most of the similar studies reported in the literature are based on observations for long periods of time. However, this comes in hand with the problem stated before regarding the difficulty of finding volunteers at no financial cost. Given the limited resources for this study, it was not possible to take the measurements over a long period of time.

Other factors that could contribute to the variations observed could be either a natural variation that may occur in the human body over a day, whether or not the individual is sedentary or variation due to a lack of reliability in the measuring process.

Measuring the human body is an extremely difficult task. In this case a single observer took all of the measurements. This observer has the experience to achieve reliable measurements, as indicated by results from an earlier study. In this study the range of variation achieved with repeated measures of similar body measurements had a relative technical error of measurement always lower than $1.5 \%$, an intraclass correlation coefficient always lower than 0.90 and a coefficient of reliability always higher than 0.95 . However, with no opportunity for repeated measures in this study, there was no confirmation that similar results were achieved.

To compare the morning measurements with the afternoon measurement it was mandatory for the landmarks placed on the body in the morning to still be visible in the afternoon. However, in many cases the marks were placed on locations that were covered, and the friction from clothing caused the landmarks to disappear over time. This may have contributed most to a lack of reliability in the results, because without precise landmarks the observer may not have performed the measurements on the exact same place in the afternoon as for the morning measurement.

The posture of the participants during the two repetitions could not be exactly the same, also contributing to possible differences in the measurements not caused by body size variation. In the first measurement session, the participants were more attentive to their posture for the measuring process. At the end of the workday, for the second measurement session the participants were less attentive to the measurement posture regardless of the constant instructions from the observer, which may have caused some discrepancies in the measurements.

Inherent impacts on reliability of the measurements also exist in the level of precision possible with the anthropometric instruments used and the measurement procedure itself. For example, measurements taken with a measuring tape or with an anthropometer can vary depending on the pressure exerted on the skin. This situation is exaggerated over soft and fat tissue where the variation can be much greater and where more errors can occur, even for trained personnel.

A more closed protocol would be preferable for a study of this type, in which the participants are monitored for the entire day in order to minimize behavioral variability. In this study, the measurement process took place in the workplace of the participants, not in a research laboratory, so that it would mimic the exact conditions of the participants' daily routines. However, the participants had to go to a specific room to perform the measurements. The contact with the researcher only occurred in the two periods during which the measurements took place, and the participants were free to do what they wanted for the rest of the time. During this time, many aspects can vary from participant to participant. People could adopt different postures within the same working posture, e.g., some people tend to lean forward while sitting and others backward; some people cross their legs and others do not. Also, other different activities such as 1 min of walking rapidly or climbing stairs could have a different effect on the measurements, because the circulation improves, there is a repositioning of some body parts and the spine either settles or stretches. In this study it was not possible to control all of these issues, which may have had some impact on the results. The ideal situation would be to measure while the study participants are still seated at their desk in a very controlled environment.

Nevertheless, the importance of acquiring data with such precision and accuracy is only important for certain types of studies. For example, in health studies where the intention is to understand the impact of working postures on the appearance of varicose veins, even the slightest variation is important to take into consideration. 


\section{Conclusions}

Working constantly in the sitting posture without any postural changes reflects several effects that can be unsafe or cause any sort of damage to workers. Leg swelling and decrease of stature are some common results of a sedentary lifestyle, including at work.

This article was intended to quantify the intraday variability of certain anthropometric measurements as a result of working in the sitting posture. The results of this study show that it is possible to identify some alterations in the anthropometric measurement during one workday. However, it was unclear whether these alterations were solely based on the sitting posture or whether they were influenced by other external factors, such as the natural variation of the human body or measurement error.

Although only a few differences in the measurements were considered statistically significant, some trends were observed that supported the hypotheses and the previously published literature - some measurements showed a tendency to increase over time (e.g., weight, waist girth) and others to decrease over time (e.g., stature, thigh girth). Most measurements behaved as expected. Nevertheless, due to some limitations of the study (such as the small sample size and the work context) some measurements behaved contrary to what was expected.

This work needs to be extended to other work situations and working postures in order to identify these variations in a more reliable way.

\section{Disclosure statement}

No potential conflict of interest was reported by the authors.

\section{ORCID}

Sara Bragança (D) http://orcid.org/0000-0002-4765-3856

Pedro Arezes (D) http://orcid.org/0000-0001-9421-9123

Miguel Carvalho (D) http://orcid.org/0000-0001-8010-6478

Susan P. Ashdown (1) http://orcid.org/0000-0002-0276-4122

Celina Leão (D) http://orcid.org/0000-0003-3725-5771

\section{References}

[1] Toomingas A, Forsman M, Mathiassen S, et al. Variation between seated and standing/walking postures among male and female call centre operators. BMC Public Health. 2012;12(1):5. doi:10.1186/1471-2458-12-154

[2] Tigbe WW, Lean MEJ, Granat MH. A physically active occupation does not result in compensatory inactivity during out-of-work hours. Prev Med. 2011;53(1):48-52. doi:10.1016/j.ypmed.2011.04.018

[3] Escorpizo R. Understanding work productivity and its application to work-related musculoskeletal disorders. Int J Ind Ergon. 2008;38(3):291-297. doi:10.1016/j.ergon.2007. 10.018

[4] Del Prado-Lu JL. Risk factors to musculoskeletal disorders and anthropometric measurements of Filipino manufacturing workers. Int J Occup Saf Ergon. 2004;10(4):349-359. doi:10.1080/10803548.2004.11076618
[5] King PM. A comparison of the effects of floor mats and shoe in-soles on standing fatigue. Appl Ergon. 2002;33(5): 477-484. doi:10.1016/S0003-6870(02)00027-3

[6] Bragança S, Arezes P, Carvalho M, et al. 3D anthropometric data collection for occupational ergonomics purposes: a review. In: Arezes PM, Baptista JS, Barroso MP, et al., editors. Occupational safety and hygiene II: 10th international symposium on occupational safety and hygiene (SHO 2014). Leiden, The Netherlands: CRC Press; 2014. p. 393-398.

[7] Katzmarzyk PT, Church TS, Craig CL, et al. Sitting time and mortality from all causes, cardiovascular disease, and cancer. Med Sci Sports Exerc. 2009;41(5):998-1005. doi:10.1249/MSS.0b013e3181930355

[8] Pi-Sunyer FX. Comorbidities of overweight and obesity: current evidence and research issues. Med Sci Sports Exerc. 1999;31(11 Suppl):S602-S608. doi:10.1097/00005768199911001-00019

[9] Winkel J, Jørgensen K. Swelling of the foot, its vascular volume and systemic hemoconcentration during long-term constrained sitting. Eur J Appl Physiol Occup Physiol. 1986;55(2):162-166. doi:10.1007/BF00714999

[10] Seo A, Kakehashi M, Tsuru S, et al. Leg swelling during continuous standing and sitting work without restricting leg movement. J Occup Health. 1996;38(4):186-189. doi: $10.1539 /$ joh. 38.186

[11] Carpentier PH, Maricq HR, Biro C, et al. Prevalence, risk factors, and clinical patterns of chronic venous disorders of lower limbs: a population-based study in France. J Vasc Surg. 2004;40(4):650-659. doi:10.1016/j.jvs.2004. 07.025

[12] Shvartz E, Gaume JG, Reibold RC, et al. Effect of the circutone seat on hemodynamic, subjective, and thermal responses to prolonged sitting. Aviat Space Environ Med. 1982;53(8):795-802.

[13] Grandjean E. Fitting the task to the man: a textbook of occupational ergonomics. Bristol, PA, USA: Taylor \& Francis/Hemisphere; 1988.

[14] Sadick NS. Predisposing factors of varicose and telangiectatic leg veins. J Dermatol Surg Oncol. 1992;18(10): 883-886. doi:10.1111/j.1524-4725.1992.tb02921.x

[15] Andersson GBJ, Murphy RW, Örtengren R, et al. The influence of backrest inclination and lumbar support on lumbar lordosis. Spine (Phila Pa 1976). 1979;4(1):52-58. doi:10.1097/00007632-197901000-00009

[16] Kroemer KH, Robinette JC. Ergonomics in the design of office furniture. Ind Med Surg. 1969;38(4):115-125.

[17] Mörl F, Bradl I. Lumbar posture and muscular activity while sitting during office work. J Electromyogr Kinesiol. 2013;23(2):362-368. doi:10.1016/j.jelekin.2012.10.002

[18] Wahlstedt K, Norbäck D, Wieslander G, et al. Psychosocial and ergonomic factors, and their relation to musculoskeletal complaints in the swedish workforce. Int J Occup Saf Ergon. 2010;16(3):311-321. doi:10.1080/ 10803548.2010.11076848

[19] Vergara M, Page Á. Relationship between comfort and back posture and mobility in sitting-posture. Appl Ergon. 2002;33(1):1-8. doi:10.1016/S0003-6870(01)00056-4

[20] van Dieën JH, De Looze MP, Hermans V. Effects of dynamic office chairs on trunk kinematics, trunk extensor EMG and spinal shrinkage. Ergonomics. 2001;44(7): 739-750. doi:10.1080/00140130120297

[21] Messing K, Tissot F, Stock S. Distal lower-extremity pain and work postures in the Quebec population. Am J Public Health. 2008;98(4):705-713. doi:10.2105/AJPH.2006. 099317 
[22] Roos E, Lallukka T, Rahkonen O, et al. Working conditions and major weight gain - a prospective cohort study. Arch Environ Occup Health. 2013;68(3):166-172. doi:10.1080/19338244.2012.686931

[23] Antunes LC, Levandovski R, Dantas G, et al. Obesity and shift work: chronobiological aspects. Nutr Res Rev. 2010;23(1):155-168. doi:10.1017/S0954422410000016

[24] Ishizaki M, Morikawa Y, Nakagawa H, et al. The influence of work characteristics on body mass index and waist to hip ratio in Japanese employees. Ind Health. 2004;42(1):41-49. doi:10.2486/indhealth.42.41

[25] Nakamura K, Shimai S, Kikichi S, et al. Increases in body mass index and waist circumference as outcomes of working overtime. Occup Med (Lond). 1998;48(3):169-173. doi:10.1093/occmed/48.3.169

[26] Linné Y, Dye L, Barkeling B, et al. Weight development over time in parous women - the SPAWN study - 15 years follow-up. Int $\mathrm{J}$ Obes Relat Metab Disord. 2003;27(12):1516-1522. doi:10.1038/sj.ijo.0802441

[27] Khosla T, Billewicz WZ. Measurement of change in bodyweight. Br J Nutr. 1964;18(1):227-239. doi:10.1079/BJN 19640022

[28] Krishan K, Sidhu MC, Kanchan T, et al. Diurnal variation in stature - is it more in children or adults? Biosci Hypotheses. 2009;2:174-175. doi:10.1016/j.bihy.2009.02.008

[29] Healey EL, Burden AM, Mcewan IM, et al. Diurnal variation in stature: do those with chronic low-back pain differ from asymptomatic controls? Clin Biomech (Bristol, Avon). 2011;26:331-336. doi:10.1016/j.clinbiomech.2010.11.017

[30] Reilly T, Freeman KA. Effects of loading on spinal shrinkage in males of different age groups. Appl Ergon. 2006;37(3):305-310. doi:10.1016/j.apergo.2005.07.004
[31] van Deursen LL, van Deursen DL, Snijders CJ, et al Relationship between everyday activities and spinal shrinkage. Clin Biomech (Bristol, Avon). 2005;20(5):547-550. doi:10.1016/j.clinbiomech.2005.01.005

[32] Corlett EN. Background to sitting at work: research-based requirements for the design of work seats. Ergonomics. 2006;49(14):1538-1546. doi:10.1080/00140130600766261

[33] Eklund JAE, Corlett EN. Shrinkage as a measure of the effect of load on the spine. Spine (Phila Pa 1976). 1984; 9(2):189-194. doi:10.1097/00007632-198403000-00009

[34] Claus A, Hides J, Moseley GL, et al. Sitting versus standing: does the intradiscal pressure cause disc degeneration or low back pain? J Electromyogr Kinesiol. 2008;18(4):550-558. doi:10.1016/j.jelekin.2006.10.011

[35] Hildebrandt VH. Back pain in the working population: prevalence rates in Dutch trades and professions. Ergonomics. 1995;38(6):1283-1298. doi:10.1080/0014013 9508925188

[36] Beynon C, Reilly T. Spinal shrinkage during a seated break and standing break during simulated nursing tasks. Appl Ergon. 2001;32(6):617-622. doi:10.1016/S0003-6870(01) 00038-2

[37] Robinson MF, Watson PE. Day-to-day variations in bodyweight of young women. Br J Nutr. 1965;19:225-235. doi:10.1079/BJN19650022

[38] International Organization for Standardization (ISO). Basic human body measurements for technological design - part 1: body measurement definition and landmarks. Geneva: ISO; 2008. Standard No. ISO 7250:2008

[39] Barroso MP, Arezes PM, Costa LG, et al. Anthropometric study of Portuguese workers. Int J Ind Ergon. 2005;35(5):401-410. doi:10.1016/j.ergon.2004.10.005 